\title{
Memoria de la Sociología Argentina ${ }^{1}$
}

Francisco Delich

Cuando este volumen apareció en Buenos Aires a comienzos de 1977 la más cruenta de las dictaduras argentinas estaba en el poder. La presidenta constitucional Isabel Martínez de Perón había sido depuesta y encarcelada por un golpe de estado cívico militar el 26 de marzo de 1976.

Este golpe de estado cerró un ciclo de medio siglo de inestabilidad política (1930-1983) que analicé en mi La Crisis en la Crisis (1996, EUDEBA, Buenos Aires) de modo que la investigación que aquí presentamos se inscribe en una coyuntura política que encuadra una coyuntura intelectual y académica.

Las Universidades públicas habían sido intervenidas por la dictadura anterior (1966-1973) y se mantuvieron intervenidas durante el gobierno constitucional de los presidentes Cámpora, Perón y Martínez de Perón entre 1973 y 1976. Recuperaron su autonomía en diciembre de 1983 durante la presidencia de Raúl Alfonsín. La misma ha sido respetada por los sucesivos gobiernos democráticos y constituye el período más largo de vigencia no interrumpida hasta el presente (2012).

Las condiciones políticas que generaba la guerra fría en curso prácticamente desde 1948 se habían exacerbado en 1962 cuando el gobierno de Cuba se declara marxista-leninista y se asocia a la Unión Soviética. A partir de entonces la llamada doctrina de la seguridad nacional impulsada desde los Estados Unidos se tradujo en controles crecientemente rígidos eventualmente policiales- de académicos e intelectuales dispuestos a mantener las reglas éticas de su profesión y su independencia de criterio.

La guerra fría es una referencia ineludible cuando se evalúa la producción sociológica de los años sesenta porque incidió directamente en su desarrollo.

Dos ejemplos pueden aproximarnos a la cuestión.

\footnotetext{
${ }^{1}$ Prólogo a la segunda edición de DELICH, Francisco, (2013), Memoria de la Sociología Argentina 1960-2010. Córdoba: Alción. pp. 7-21.
} 
En 1964 se denunció en Chile la existencia de una investigación en curso sobre los movimientos sociales y revolucionarios, patrocinado por el Ejército Norteamericano y la CIA (Central de inteligencia norteamericana) con un presupuesto extraordinario de seis millones de dólares. Se conoció como el plan Camelot y desató una gran controversia inmediatamente tanto en medios académicos norteamericanos como latinoamericanos.

Detalles de la cuestión pueden verse en Myron Glazer y Penna Glazer (1968) y sobre todo en un artículo de una figura muy respetada de la sociología estadounidense como Irving Horowitz (1965) que compartió la indignación de la Academia.

Años después se puso en marcha una gran investigación empírica en Chile sobre marginalidad social que dirigió José Nun, precedida de un examen y debate teórico del mejor nivel y una completa honestidad intelectual explicitando sus referencias desde el comienzo escribiendo: en este sentido el materialismo histórico constituirá el universo de mi discurso (Nun: 1969:178) a la que siguen otras definiciones inscriptas en el mismo razonamiento.

Sin embargo, el patrocinio de la investigación por parte de la Fundación Ford y el clima que se vivía en la izquierda chilena pusieron bajo sospecha la investigación que debió ser interrumpida antes de fructificar completamente aunque el aporte teórico que produjo en torno al concepto de marginalidad fue muy estimulante. ${ }^{2}$

El financiamiento de una investigación por parte de una Fundación norteamericana no es asimilable al financiamiento de la CIA y el Ministerio de Defensa norteamericano.

No obstante la sensibilidad en las ciencias sociales y frente a las manipulaciones del financiamiento hizo que la Universidad de Buenos Aires tomara -antes de esa fecha- una decisión drástica: no recibiría en adelante ninguna clase de subsidios o ayuda económica externa.

Cuando se instalan las dictaduras a partir de 1966 en nuestro país el criterio se mantuvo de modo que los investigadores que no recibían apoyo del Estado para sus investigaciones estaban impedidos de solicitar y recibir fondos externos.

Esta resolución de la Universidad de Buenos Aires fue derogada en 1984 con el reconocimiento de la autonomía universitaria por el Congreso de la Nación.

\footnotetext{
${ }^{2}$ Un número extraordinario de la Revista Latinoamericana de Sociología 2-69 fue dedicado al tema y el planteo de la marginalidad.
} 
Los efectos de la guerra fría se potenciaban con las dictaduras en curso en el cono sur de la región, estrictamente se implicaban porque estas encontraban legitimidad en su lucha contra el comunismo (sic) y se traducían en una simplificación y reducción de opciones intelectuales.

En efecto el enfrentamiento político durante la dictadura se expresa inevitablemente en la formación de un bloque opositor en torno a la reivindicación de la Democracia, como fue extremadamente claro durante la dictadura de 1967-1983 y se expresó en la revista Crítica \& Utopía que encontró un muy amplio espacio de opinión entre los científicos sociales.

En el breve período de autonomía universitaria (1956-1966) se produjo un episodio mayor en la historia de la sociología argentina, la irrupción de lo que Gino Germani llamó sociología científica, particularmente en la Universidad de Buenos Aires con repercusiones limitadas en el interior del país.

Este impulso lo lideró el propio Germani a partir del impacto de su obra La estructura social argentina. Editada por Raigal en 1954 la obra tuvo una rápida repercusión más por razones políticas que sociológicas.

El prestigio en las ciencias sociales fue algo posterior pero más duradero hasta convertirse en un clásico de la sociología latinoamericana.

Gino Germani había colaborado en la organización del Censo Nacional de 1947 y decidió utilizar sus resultados de una manera novedosa, para trascender la descripción sociográfica y controlar indicadores de modernización de la sociedad como las tasas de urbanización extremadamente altas para la época, en relación a América Latina y comparable con algunas tasas europeas, aproximarse a una elaboración del sistema de estratificación social y en particular a las clases sociales, confirmar a través de la evolución censal la importancia de la inmigración en la conformación histórica de la sociedad argentina.

El libro tiene una breve aunque erudita introducción teórica acerca de la noción de estructura social y luego el despliegue de las observaciones a los resultados censales.

Una cita no ha llamado suficientemente la atención. Germani menciona a Karl Polanyi autor de un libro excepcional de los años treinta The great transformation para analizar los efectos de la crisis de 1929 y la posterior consolidación de la sociedad industrial norteamericana. 
La evolución de la estratificación social argentina es muy nítida a lo largo del siglo y anticipa lo que estos años se puede comprobar fácilmente y no solamente a través de los censos: su carácter moderno, la expansión de las clases medias urbanas y rurales, la secularización del estado entre otras. Era importante su aporte por la prolijidad y precisión de sus datos y su estrecha relación con hipótesis fundantes para el conocimiento de la sociedad argentina.

Pero es el último capítulo del libro el que merecerá la mayor atención y tendrá las mayores repercusiones. El capítulo XVI se titula diferenciación de las actitudes politicas en función de la estructura ocupacional y de clases.

Germani escribe el estudio de la conexión entre estructura de clase ideologias constituye en la actualidad uno de los capitulos de mayor interés de la sociología y la psicología social (1954:247) y más importante todavía esta toma de posición Toda una disciplina especial - la sociología del conocimiento - se ha constituido en torno a este tema - aunque por supuesto su objeto no se limita meramente al pensamiento politico y se extiende al problema mas general del condicionamiento social de todas las esferas del conocimiento. Si quedaba alguna duda acerca de la orientación teórica agrega no corresponde ocuparnos aqui de la extensa bibliografía teorética que se ha ido acumulando desde las clásicas obras de Marx y Engels y otros (1954:247).

Es un ejercicio de geografía electoral como le llamó A. Siegfried en Francia o de ecología política como le llaman en Estados Unidos. Aunque el origen de los datos pertenecen a fuentes diferentes, explica Germani la distribución censal de la población y los resultados electorales que reconoce a todos los habitantes de un área y el resultado electoral que registra el voto solamente de los mayores de 18 años varones y argentinos (las mujeres después de 1947) sin embargo se puede establecer una correlación entre la zona ecológica y el voto.

La conclusión del ejercicio era inadmisible para muchos de los compañeros de Germani. También para él mismo que lo publicó sin embargo porque desarrolló una explicación diferente. ${ }^{3}$

Desde 1946 los partidos comunista y socialista caracterizaban como fascista al régimen recién instalado en el gobierno. Las relaciones del gobierno de Perón con el antiguo régimen nazi, sus relaciones durante el

\footnotetext{
${ }^{3}$ En su Autoritarismo, fascismo e classi sociali (1975) Il Mulino, Bologna se ocupó extensamente de los fenómenos populistas autoritarios que vinculó a la movilidad social entre otras dimensiones de la modernización.
} 
gobierno de Hitler y posterior a su caída (otorgamiento de visas para antiguos jerarcas que pasaron a residir en Argentina).

Hasta 1945 ambos partidos de izquierda disputaban el control de la CGT. Hacía años que habían desplazado a los anarquistas y entre ambos prácticamente monopolizaban el control del movimiento obrero argentino.

¿Se podía pensar en esos años en un salto brusco de esta naturaleza en el movimiento obrero argentino que en menos de cinco años abandonara el viejo molde de izquierda?

Estar era la hipótesis de Germani. Efectivamente la clase obrera había votado por Perón en 1946. Efectivamente lo acompañaría después.

Todas las investigaciones posteriores sobre la evolución de la clase obrera y los sindicatos tomaron la hipótesis y el texto de Germani como un punto de partida. La discusión política entre los partidos políticos y el partido peronista en cualquier denominación debió alterar sus parámetros. Los estudiantes de sociología de comienzos de los años sesenta advirtieron que había una sociología distinta a construir.

Ninguna obra sociológica publicada entre 1950 y 1975 - el período al que se refiere el texto - tuvo el interés, la trascendencia de esta obra pionera en la sociología argentina y latinoamericana.

La inestabilidad política, el péndulo democracia-golpe de estado que se sucedió durante medio siglo no impide la mutación de la sociedad, solamente la oculta; el movimiento y el ruido de la superficie política invisibiliza las trasformaciones sociales. Son muchos quienes se confunden.

También los prejuicios y barreras ideológicas contribuyen a distorsionar y desviar la mirada. Los partidarios de la revolución desprecian los cambios como meros retoques y los partidarios del cambio celebran cada innovación tecnológica u otra como el anticipo de transformaciones mayores.

Las estructuras sociales no se conmueven fácilmente pero se erosionan constantemente.

Por ejemplo el cambio cultural que implica una proporción creciente decidiendo no tener hijos se manifiesta tardíamente en los censos y más tardíamente aún en la perspectiva de los valores sociales. Lentamente la maternidad deja de ser un valor en sí y arrastra de manera descendente a valores asociados a la maternidad mientras aumenta el consenso acerca de 
otros valores atinentes a la mujer como su independencia o vocación profesional. No obstante en el conjunto social nada parece haber cambiado.

Cambio y Revolución fueron dos constantes del debate sociológico y meta sociológico durante los años que se examinan, particularmente durante la década del sesenta. La modernización como agente del cambio en un caso, la lucha de clases en el otro, en ambos el nivel es siempre macrosociológico. Las corrientes subterráneas de la acción social no son visibles.

Estrictamente si ambos términos coexistían en conflicto es porque la sociedad argentina tenía fuerzas y actores sociales que a partir de mutaciones reales y sensibles se disputaban el futuro, era más un debate de proyectos que de tendencias o si se prefiere de un futuro suficientemente abierto para que ambas opciones tuviesen señales favorables.

Se puede argumentar que este tipo de conflictos es saludable en la sociedad porque está definiendo su futuro a partir de condiciones presentes. La sociedad no está orientada por el pasado sino por proyectos y opciones de futuro.

El signo de los tiempos era la crisis de viejas estructuras y viejas formas de control social. La aparición de actores viejos que cobran una nueva dimensión como la clase obrera o actores nuevos que demandan un espacio de acción como las mujeres por ejemplo.

La sociología en ebullición y expansión ofrecía una mirada más amplia, conceptualmente más variada y rica que las exposiciones de cátedra y los ensayos supuestamente filosóficos sociales. Y un nuevo método capaz de aportar información pertinente a las hipótesis en curso.

La primera parte de este libro fue un informe presentado a un congreso latinoamericano de Sociología; es un testimonio de aquellos debates. La renovación aportada por Germani, la reintroducción de la problemática de la modernidad como teoría de la modernización, los primeros análisis de la marginalidad que dieron lugar a discusiones teóricas y político-científicas (1956-1966) y generaron nuevos datos pertinentes para el análisis, desplazaron otros caminos valiosos para el conocimiento. Apareció en 1970 y esta es su primera reedición.

Germani reunió la sociología de cátedra y el ensayo como pre sociología como sostuvo en distintos estudios dedicados a la sociología latinoamericana. 
En cierto sentido es correcto mirado desde la sociología profesional como actividad, como estilo pero la descalificación no tenía en cuenta el interés cognitivo de hipótesis atractivas para explorar con otra metodología.

La sociología de cátedra no era un conjunto amorfo ni homologable. Había profesores talentosos que desafiaban la mediocridad de las universidades intervenidas. Había ensayos, análisis de coyuntura que aportaban miradas y proposiciones que permitían establecer un diálogo creativo.

Entre otras fue razón para designar como sociología de frac una forma de sociología en retirada pero que había sido institucionalmente poderosa durante los períodos militares como una sociología de frac, más que una prenda en desuso, solemne y acartonado, un modo de pensar vacío que reunía orientaciones doctrinarias e ideológicas muy diversas como se mencionan en el texto.

No eran políticamente inocentes. Cuando Alfredo Poviña denuncia a la sociología comprometida como se menciona en el texto estaba refiriéndose a los jóvenes sociólogos que intentaban acercarse de un modo no ideológico a la realidad. Era una auténtica provocación que tuvo respuestas inmediatas como la que constan luego.

White collar, trabajador de cuello blanco eso queríamos ser per las circunstancias políticas no lo permitían. El empleo universitario no estaba disponible, (salvo el período 1956-1966) tampoco instituciones estatales ahora tan espléndidas para la investigación como el CONICET, ni el financiamiento privado accesible solo para aquellos afines al establishment.

Lo que llamé descamisados constituyeron un grupo peronista que se incorporó a las cátedras de sociología de la Universidad de Buenos Aires tras el golpe de estado de 1966. Debe recordarse que el peronismo apoyó el golpe de estado en particular la CGT liderada por un dirigente metalúrgico llamado José Ignacio Rucci que sería asesinado durante el gobierno constitucional peronista.

Se llamaron a sí mismos las cátedras nacionales, expresaron en revistas (Antropología del Tercer Mundo), libros y publicaciones de cátedras. ${ }^{4}$

A propósito de la publicación de un libro de Arturo Jauretche, el medio pelo de la sociedad argentina y a pedido de la revista latinoamericana de sociología que editaba el Instituto Di Tella bajo la dirección de Juan

\footnotetext{
${ }^{4}$ Para una caracterización apropiada de esta corriente puede leerse a Roberto Carri (1973) Poder imperialista y Liberación Nacional - Las luchas del peronismo contra la dependencia. Efece. Buenos Aires. Roberto Carri se incorporó a Montoneros y está desaparecido.
} 
Francisco Marsal publiqué una nota crítica que mereció una respuesta airada de uno de los integrantes de las cátedras nacionales.

Puede verse allí con claridad la distancia que mediaba entre corrientes sociológicas. ${ }^{5}$

El gobierno surgido de aquel golpe que encabezaba el General Onganía disolvió los partidos políticos e incautó sus bienes, de marcada orientación católica, conservador-liberal en materia económica fue imaginado como se señala en el texto - como un Bismark argentino que re fundara la nación con un modelo corporativo que parecía extraído de un manual falangista. Entre otros objetivos se proponían también terminar con el liderazgo del expatriado General Perón. ${ }^{6}$

La fantasía política de una dictadura arcaica finalizó un año después de la insurrección cordobesa de mayo de 1969 como verse en mi libro crisis y protesta social. Córdoba mayo de 1969 (varias ediciones).

En el camino la dictadura dejó una universidad intervenida diezmada de sus mejores cuadros científicos exiliados para siempre, un espacio intelectual anacrónico cargado de acusaciones innobles contra docentes e investigadores de izquierda.

Gino Germani el ícono de la renovación perseguido por antisemitas abandonó el país. Contratado en Harvard donde se jubiló regresó a sus orígenes y falleció en Roma en 1979.

No solo por antisemitas. Cuando apareció el deslumbrante y ahora un clásico de la mejor sociología Wrigt Mills (1959) The sociological imagination Oxford University Press, y el Fondo de Cultura Económica decidió su traducción al español encargaron su presentación a Gino Germani, quien defendió la artesanía que Mills proponía tanto como su carencia de prejuicios ideológicos y su pasión por investigar empíricamente.

Milcíades Peña era un intelectual marxista que editaba una revista excepcionalmente útil con oferta de información agudamente analizada; se titulaba Fichas y ponía al alcance de los estudiantes de sociología (y por supuesto al alcance de cualquiera puesto que se vendía en los puestos de periódicos) un tipo de análisis novedoso dentro y fuera del marxismo.

Sin embargo M. Peña atacó duramente a Germani en una artículo cuyo título hacía innecesaria su lectura para la comprensión del mensaje:

\footnotetext{
${ }^{5}$ Roberto Carri un sociólogo de medio pelo y Francisco Delich Respuesta ambos artículos en la Revista Latinoamericana de Sociología, 1968 número 1.

${ }^{6}$ Una interpretación del gobierno de Onganía se puede leer en Liliana de Riz (2000) La política en suspenso 1966-1976. Paidos. Buenos Aires.
} 
Gino Germani o las enojosas reflexiones de la paja seca frente al fuego (Fichasjulio de 1964) se titulaba. La Revista fue prohibida por la dictadura en 1966.

Durante los años a los que se refiere este informe un fenómeno novedoso se produjo en las Ciencias Sociales de América Latina. Las dictaduras produjeron un doble efecto no querido: el exilio, el éxodo de docentes e investigadores que encontraron refugio en México, Venezuela en la región o Francia, Suecia, Inglaterra en Europa permitieron la formación de posgrado y doctorado de centenares de jóvenes cientistas sociales. Estos jóvenes descubrieron transitando estos países ajenos la originalidad de estas sociedades y muchos encontraron un objeto de análisis atractivo capaz de articular la identidad con la solidaridad, la profesión con la vocación.

Las respuestas de los científicos sociales a los golpes de estado y subsiguientes dictaduras en Brasil (1964) y Argentina (1966) fue individual porque los afectados directamente eran docentes o investigadores. Pero casi inmediatamente los centros de investigación afectados (o que no era afectados directamente) se reunieron y crearon instituciones académicas capaces de interpelar gobiernos y sociedades sino también promover la cantidad y calidad de la producción, formar jóvenes investigadores e incluirse en redes extrarregionales.

CLACSO (Consejo Latinoamericano de Ciencias Sociales) fue fundado en 1968 en la ciudad de Caracas por los centro de investigación más importantes y prestigiados de la región. Una década después registraba más de cien centros de investigación asociados.

Clacso fue establecida como entidad no gubernamental y dedicada exclusivamente a la investigación.

Cuando se crearon entidades similares en Europa, Asia y África, Clacso se incorporó al ICDA (International Cooperation Developpment Association) la primera red de organizaciones de Ciencias Sociales del planeta.

Unos años antes, en 1958 la UNESCO había fundado en Santiago de Chile un instituto docente de alto nivel para la formación de posgrado, FLACSO (Facultad Latinoamericana de Ciencias Sociales) y contratado para la docencia a un grupo de sociólogos europeos entre los cuales Alain Touraine, Peter Heinz y J. Galtung. 
A diferencia de CLACSO, la fundación de FLACSO tenía origen en algunos estados y mantiene ese carácter a cincuenta años de su creación.

El golpe de estado de Pinochet en Chile y las persecuciones desatadas contra estudiantes chilenos y no chilenos y entre los profesores de cualquier nacionalidad decidió el traslado de FLACSO a Buenos Aires donde se mantenía el gobierno democrático, pero luego, cuando las persecuciones amenazaron a estudiantes y docentes debió trasladas su sede definitivamente a Costa Rica la más estable democracia de América Latina.

La proliferación de dictaduras no impidió la fundación de nuevas sedes de FLACSO y con el correr de los años se fueron agregando una docena de sedes nacionales a la inicial sede chilena.

Este crecimiento institucional potenció las relaciones intra regionales y consolidó las tendencias intelectuales hacia una creciente autonomía del pensamiento. La originalidad del pensamiento de Raúl Prebisch desde la CEPAL (Comisión Económica para América Latina) organismo dependiente de las Naciones Unidas, señalando la asimetría del comercio internacional que producía términos desfavorables para América Latina, la necesidad de la reforma agraria como condición para el desarrollo, la denuncia del carácter parasitario de las oligarquías vernáculas fueron otras tantas contribuciones a un nuevo pensamiento científico social.

La presencia en la CEPAL de José Medina Echeverría un sociólogo español exiliado de la guerra de España (1936-1939) estrechó las relaciones entre los economistas y los sociólogos y permitió la ampliación de los horizontes multidisciplinarios para análisis totalizadores de los fenómenos sociales.

Medina Echeverría acogido por el gobierno de México luego de la derrota republicana y el triunfo falangista, editó la Economía y Sociedad de Max Weber que solo había sido-parcialmente - traducido al español por Talcott Parsons unos años antes. Docente de la Universidad de Chile tuvo entre sus discípulos más conocidos a Enzo Faletto.

Este último y Fernando Henrique Cardozo elaboraron la conocida teoría de la dependencia cuya presentación hicieron en un libro extremadamente difundido. ${ }^{7}$

\footnotetext{
${ }^{7}$ José Media Echeverría escribió entre otros libros deliciosos Presentaciones y Planteos Papeles de Sociología Instituto de Investigaciones sociales de la UNAM en 1953 donde ofrece una visión original de M. Weber. Luego en Chile asumió la responsabilidad de la investigación en Cepal y elaboró los primeros textos sobre los aspectos sociales del desarrollo consideraciones sociológicas sobre el desarrollo económico en América Latina. Ediciones La Banda Oriental, Montevideo 1964.
} 
A fines de la década del sesenta -lo que llamaré las corrientes latinoamericanistas en las ciencias sociales- se habían difundido y consolidado institucionalmente. El pensamiento propiamente regional -producido en y por latinoamericanos- estaba fuera de las ciencias sociales en ensayos, en la literatura y en los debates ideológico políticos.

De modo que la renovación teórica, temática y metodológica en la sociología argentina estuvo ligada - acaso por primera vez - a las corrientes y discusiones latinoamericanas; las novedades cognitivas que las investigaciones empíricas aportaban, permitieron un fortalecimiento de estrategias de investigación que utilizaban marcos teóricos apropiados.

Si en los años cincuenta la difusión que se hacía en las cátedras de marcos teóricos euro céntricos o norteamericanos eran inmediatamente seguidos por adaptadores locales que establecían rangos de diferencia empírica o históricas con éstos, en las décadas siguientes asistimos a elaboraciones teóricas capaces de incluirse en discusiones planetarias.

Disciplinas de escaso desarrollo (comparado con Perú, Guatemala o México) como la Antropología, encontraron rápido desarrollo y contribuyeron (en particular la antropología social) a un diálogo creativo con las nuevas corrientes sociológicas.

El período que estudiamos fue claramente un momento de coincidencia de estilos, algunos desaparecieron y otros encontraron nuevas expresiones a partir del cauce común científico-teóricas y metodológicas con marcada tendencia al análisis local o comparativo latinoamericano.

El texto se publica tal como apareció en 1977, sin modificaciones (a excepción de un post scriptum irrelevante) porque tiene un valor testimonial: así se escribía, así se discutía y se confrontaba; están las lecturas, los juicios objetivos y subjetivos, la sociedad argentina en trazos gruesos, los actos - y autores - de la disciplina.

Se escribió entre una dictadura y otra, se editó en una democracia latinoamericana pero se distribuyó y se leyó a comienzos de la dictadura que había prohibido decenas de libros, entre ellos la $2^{\mathrm{a}}$ edición de mi Crisis y Protesta Social (Siglo XXI de Buenos Aires). En 1981 se prohibió también la circulación de Crítica ê Utopia incluida en una lista de publicaciones pornográficas según informó el diario La Razón de Buenos Aires.

He mencionado un libro mayor de aquellos años pero no he mencionado un hecho histórico mayor que no consta explícito pero circula en 
el meta texto: el cordobazo como se conoció la insurrección popular que puso fin a la dictadura de Onganía.

Las consecuencias no impactaron solamente en el sistema político. Onganía fue relevado por las Fuerzas Armadas un año después y se restablecieron los partidos políticos. Se concursaron las cátedras en las Universidades públicas y se abrió el camino para la recuperación institucional en los dos años siguientes.

El efecto se hizo sentir en la propia sociología. Lo que llamé la sociología de frac no podía analizar un fenómeno social de esta naturaleza que desafiaba cualquier abstracción. Tampoco los llamados descamisados, porque su estrategia intelectual estaba ligada a una estrategia política colapsada. Algunos de sus integrantes se radicalizaron, otros cambiaron de perspectiva. Quedó en pie la sociología llamada científica que tampoco podía analizar en sus propios límites aquella protesta (en realidad una sucesión de movilizaciones y protestas populares que culminaron en Córdoba).

Córdoba, febrero de 2012. 